\title{
Motivating Reason to Slow the FaGtive TURN IN EPISTEMOLOGY ${ }^{1}$
}

\author{
J. DRAKE
}

It is an intriguing time to be thinking about the factivity of reasons. As factive views of reasons are gaining favor in epistemology, practical philosophy has been increasingly considering the possibility of nonfactive views. This paper is part of a larger project that encourages more exchange between theorists of practical and epistemic reasons. Such an exchange would be especially fruitful, I think, vis-á-vis the issue of factivity. The primary aim of this paper will be to slow the factive turn in epistemology, as it were, by appealing to points about the factivity of practical reasons. I suspect that the implication of the main argument of this paper will strike many as surprising; it shows that, in order to successfully establish the view that normative epistemic reasons are facts, one must discredit the view that motivating practical reasons need not be facts.

The course of the paper is as follows. I begin in the first section with some preliminary remarks about two standard distinctions in the theory of reasons: that between motivating and normative reasons, and that between practical and epistemic reasons. I also briefly spell out what the Factive and Nonfactive View of each of these looks like. I proceed in the second section of the paper to lay out an important claim on which my argument relies: the claim that our positions on the factivity of epistemic and practical normative reasons should agree. I defend this claim of uniformity from an initial concern, namely, that epistemic reasons owe their distinctive character precisely to their relation to the truth. That being the case, one might think that we have a special reason to think that epistemic reasons are facts - one which does not also lend support to the idea that practical reasons are facts. But I show that this concern is misguided.

\footnotetext{
${ }^{1}$ An earlier version of this paper was presented at the Factive Turn in Epistemology Workshop in Vienna, and it has benefited from my interactions with those who attended - especially Tim Williamson. I owe thanks to Veli Mitova and an anonymous referee for helpful feedback on a draft of the paper; and also to Maria Alvarez and Juan Comesaña for discussion of earlier materials. I am above all indebted to Dan Bonevac, David Sosa, and Jonathan Dancy for discussing these ideas with me as I developed them and transitioned through several drafts of the paper.
} 
With this claim of uniformity on board, I spend the next three sections of the paper establishing the following claim: if motivating reasons need not be facts, then normative reasons need not be facts. Focusing my attention on practical reasons, I begin in the third section by explaining why one might think that motivating reasons need not be facts. I then move in the fourth section to motivate the thought that in some cases where $A \Phi$ s for the reason that $r$ and it is not the case that $r, A$ 's $\Phi$ ing is rational; not only can an agent act in the light of a falsehood, but an agent can also act rationally in the light of a falsehood. I also claim that a plausible conception of rationality is one on which $A$ 's $\Phi$ ing can be rational only if $A$ 's $\Phi$ ing is done for some good reason. If this is all correct, then some false reasons for which agents act must also be good reasons - and so some normative reasons must not be facts.

I connect all of the dots in the fifth section by briefly laying out my main argument against the factive turn in epistemology. In conjunction with the claim of uniformity from the second section, the previous three sections give us what we need to mount a somewhat surprising argument against factive views of epistemic normative reasons. In the sixth section I address three objections. I first address the common argument that motivating reasons cannot be falsehoods due to the role they play in explaining actions. I then treat two further objections that try to thread the needle a bit, by forcing a wedge between rationality and reasons-responsiveness. According to the first of these, since in the cases of interest $A$ has no good reason to $\Phi$, we must stop short of attributing rationality to $A$ 's Фing. According to the second of these, we might concede that in these cases $A$ 's $\Phi$ ing is rational, but not in any sense that implies that $A \Phi_{\mathrm{S}}$ for a good reason. I conclude in the seventh section by expressing some hesitation about where my arguments are leading. One might grant the core argument of my paper - that the factivity of motivating and normative reasons rise and fall together - and simply use it as a reductio against the view that practical motivating reasons need not be facts. I suggest that this is not as easily done as one might initially suppose. 


\section{PReliminary Remarks}

As I said, I am primarily concerned to establish the claim that: if motivating reasons need not be facts, then normative reasons need not be facts. I have also said that my demonstration of this claim will operate primarily on "practical" reasons, but with clear implications for "epistemic" reasons. Such a project calls for clarifications on three fronts.

First, there is the standard distinction between motivating and normative reasons. ${ }^{2}$ Borrowing from the literature, we can say that a motivating reason is a consideration in the light of which an agent acts. For example, suppose you see me running through the halls. You might ask me why I am running through the halls. I would likely respond by presenting the consideration(s) which motivated me to run through the halls (for example, the consideration that I am late to give my eleven o'clock lecture). You would likely be satisfied with such a response, as it would help you to make sense of my action. But you might also be interested in whether there is, as we might say, any good reason for me to be running through the halls. Here you are looking for what is called a normative reason: a consideration that counts in favor of a response. In normal cases (such as the one considered here), the agent's motivating reason will be a normative reason. In telling you that I am late to give my lecture, I have presented you with that consideration which casts my action in a favorable light; I have told you not only why I am running, but also, perhaps, why I should be running.

Recently, there has been debate concerning the "factivity" of both kinds of reasons. In practical philosophy and action theory, there has been much more debate about the factivity of motivating reasons. In that debate, there are two main views. One is the

Factive View : in order for $A$ to $\Phi$ for the reason that $r$, it must be the case that $r$.

2 Too many to name employ this common distinction, which is perhaps owed to Michael Smith [1992: 329]. For relevant introductions to the distinction, though, see Jonathan Dancy [2000: 1ff] for something brief, and Maria Alvarez [2010] for something more thorough. Cases like the ones I will discuss might impress upon us the idea that we need a third class: explanatory reasons. Alvarez [2010; 2016] has done well to argue for this position, but I cannot treat it here. 
The competitor to this view is the Nonfactive Viewm, which is just the denial of the Factive Viewm. ${ }^{3}$ According to the Factive Viewn, I cannot be running through the halls for the reason that I am late unless I really am late. The Nonfactive Views denies this, and holds that my reason for running might be that I am late even if I am not really late. The debate about such claims is distinct from the debate about the factivity of normative reasons, which has received more attention in recent epistemology. In that debate, there are also two main views. One is the

Factive Viewn: in order for $r$ to be a reason for $A$ to $\Phi$, it must be the case that $r$.

The competitor to this view is the Nonfactive Viewn, which is just the denial of the Factive Viewn. ${ }^{4}$ Of course, in this context, the phrase "be a reason for $A$ to $\Phi$ " should be taken not motivationally, but rather as, roughly, "count in favor of $A$ 's $\Phi$ ing”. So, independent of what my (motivating) reason is for running through the halls, proponents of the Factive Viewn will hold that my being late can only count in favor of my running if I really am late. Those who endorse the Nonfactive Viewn will deny this claim, holding that my being late might count in favor of my running regardless of whether I really am late.

These clarifying remarks have so far involved an example of so-called "practical" reasons; but, as I have noted, these issues manifest vis-á-vis so-called "epistemic" reasons as well. This is

${ }^{3}$ I have modified the labels here from Dancy [2011], who has argued [2000; 2003; 2011; 2014] for the Nonfactive Viewm extensively. Juan Comesaña and Matthew McGrath [2014], as well as Mark Schroeder [2008], defend a nonfactive view of having reasons; but the connection to acting for a reason is not completely clear. Constantine Sandis [2013] claims to endorse the view; but since he denies that false motivating reasons have explanatory power, it is not clear that his position should be grouped with Dancy's. In epistemology, David Enoch [2010: 984] seems to express sympathy for the view in passing.

The Factive View is far and away the dominant view in the literature on practical reasons. A relevant sample includes Alvarez [2010], Donald Davidson [1980], Jennifer Hornsby [2008], John Hyman [2011], and John McDowell [2013]. In epistemology, Timothy Williamson [2000; 2014] falls in the Factivist camp; and Clayton Littlejohn [2012: 149ff] also seems sympathetic to a kind Factive View.

${ }^{4}$ In the literature on practical and moral reasons, the Factive Viewn is so far in the majority that it is often assumed without argument. Indeed, the assumption is often that reasons for acting are facts, and the debate is about what kind of facts they might be. See Parfit [2011: 31] for an example.

In the literature on epistemic reasons, things are a bit different; and the debate about the factivity of epistemic normative reasons might be hiding under the label "the factivity of evidence." On that topic, the Factive Viewn of epistemic reasons is only recently coming in to some favor, with the work of those like Williamson [2000] and Littlejohn [2012; 2013a; 2013b]. See Thomas Kelly [2008] for a nice discussion on how this debate has developed. 
the third and final front on which my project is in need of clarification. Borrowing from the literature is less useful in making this distinction, but I shall try to follow roughly the distinction as laid out by Joseph Raz. ${ }^{5}$ The distinction between practical and epistemic reasons is most easily thought of as a distinction between two kinds of normative reasons. According to this framework, practical reasons are considerations that owe their normative force to their relation to values. Epistemic reasons, on the other hand, are considerations that owe their normative force to their relation to the truth. For example, my being late to give my eleven o'clock lecture seems to be a practical reason: it favors my running through the halls, and it so favors in virtue of its relation to certain values (such as that of being punctual). As such, this is a practical reason; but there are epistemic reasons nearby. Suppose that you ask me why I believe that I am late, and I respond that the clock in my office reads quarter-past eleven. As such, this fact about my clock seems to be an epistemic reason: it favors my believing that I am late, and it so favors in virtue of its relation to the truth (about what time it is).

\section{UNIFORMITY}

So much for preliminaries. I said at the outset that this paper is a part of a larger project that encourages more exchange between theories of practical and epistemic reasons. But, given the deep difference in the respective natures of practical and epistemic reasons, one might worry about the prospective fruitfulness of such an exchange. If there is legitimate reason to worry, the main argument of this paper might be robbed of some of its force. That is because the argument relies in part on the claim that I will call

Uniformity: ceteris paribus, the best theory of reasons will hold just one position about the factivity of reasons, which is true of every kind of reason.

\footnotetext{
${ }^{5}$ See Raz [2011: 36-58] for a particularly nice explication of this distinction, which I take to be standard. Notice that this crucial distinction remains intact even on views according to which truth is a kind of value (and epistemic reasons can therefore be thought of as a kind of practical reason). The distinction would then be grounded in a distinction between two kinds of values. Thanks to an anonymous referee for encouraging me to address this possibility.
} 
I mean this claim to apply within each of the realms of motivating and normative reasons independently, but across normative realms (moral, epistemic, practical, aesthetic, or otherwise) therein. Suppose, for example, that we become convinced that the Factive Viewn of epistemic reasons is correct. Then, according to the principle of uniformity, there is theoretical pressure to endorse the Factive Viewn of practical reasons. Similarly: if one becomes convinced that the Nonfactive Viewn of practical reasons is correct, then one is under some theoretical pressure to endorse the Nonfactive Viewn of epistemic reasons. For my part, I find this commitment to uniformity to be simply intuitive. I also know of no good argument against it; and so I will treat it as a kind of working assumption.

Plausible though the principle of uniformity may be, one may have doubts about it because of the difference between practical and epistemic reasons just laid out. The distinguishing mark of epistemic reasons is supposed to be their relation to the truth (practical reasons stand in no such special relation); and the debate about the factivity of reasons is, essentially, a debate about whether something must be true in order to be a reason. Should we not, then, expect a deep difference between practical and epistemic reasons on the issue of factivity? I think not. There are two questions that need to be separated here. One is the question of what makes something a reason at all; another question is what makes something a reason of a particular kind. The distinction just laid out, of course, gives a standard answer to the second question. But that answer does not imply any answer to the first question. Suppose that $r$ is an epistemic reason for some agent $A$ to $\Phi$ (where $\Phi$ ing is, say, believing that $p$ ). The standard distinction tells us that what makes $r$ an epistemic reason to $\Phi$, rather than a practical reason to $\Phi$, is the relation that $r$ bears to the truth of $p$ (for example, $r$ might make it more likely to be true that $p$ ). This, of course, says nothing about whether $r$ itself is true; it is not the truth of $r$, but rather the effect that $r$ has on the truth of $p$, that is important for making the standard distinction. But the debate over the factivity of reasons, applied here, would be a debate about whether $r$ itself must be true in order to be a reason. So we can see clearly that the special relation that epistemic 
reasons bear to the truth is really no reason at all to suspect that they will be deeply different from practical reasons vis-á-vis the issue of factivity.

If the principle of uniformity is correct, there may be serious implications for theorizing about reasons - especially if the natures of motivating and normative reasons can be connected in the manner I shall go on to claim in this paper. Together, these two claims amount to the thought that theories of reasons must take just one position on factivity, which holds for all kinds of reasons: motivating, normative, practical, and epistemic. Consequently, someone who sets out to establish the factivity of normative epistemic reasons, for example, will be saddled with defending the factivity of these other varieties of reasons as well.

\section{AGting in the Light of a Falsehood}

With these initial remarks in mind, I move in this section toward my main claim that if motivating reasons need not be facts, then normative reasons need not be facts (or, in other words, if the Nonfactive Viewn is correct, then the Nonfactive Viewn is also correct). In this section I will explain why one might think that motivating reasons need not be facts - or (alternatively), that in order for $A$ to $\Phi$ for the reason that $r$, it need not be the case that $r$. To help with this, I will employ variations of a case that has become somewhat standard in the literature on the factivity of practical motivating reasons. ${ }^{6}$

SKATING: Imagine a pond that has thin ice in the middle. Edna takes it that the ice in the middle of the pond is thin. So, when she skates, Edna keeps to the edge of the pond. You are on a nearby hill, and you see Edna skating. You ask her why she is skating as she is, and she tells you that the ice in the middle of the pond is thin.

I take it to be rather natural and uncontroversial to understand this case such that Edna's reason for skating near the edge of the pond is that [THIN ICE]: the ice in the middle of the pond is thin.

\footnotetext{
${ }^{6}$ I am adapting this example from Hornsby [2008: 251], which, as far as I know, traces back to Gilbert Ryle [1949: 117-118] — although its more contemporary usage may be due to Peter Unger [1975: 209-211].
} 
When I say that I take it to be natural and uncontroversial, I am speaking pre-theoretically: there is, pre-theoretically, no reason to deny this understanding of the case (or to privilege another understanding over it). At the very least, we can say that in skating near the edge of the pond, Edna is responding to the consideration that [THIN ICE].

But independent theoretical reason for taking the case in this way can be provided. In SKATING, you are observing Edna's behavior with no view about how things are with the ice. You ask Edna why she is skating near the edge of the pond. Insofar as, when we ask such questions, we take ourselves to be asking for what reason the agent in question is so acting, we express some sympathy for the claim that

motivating reasons play an explanatory role: if $A \Phi_{\mathrm{s}}$ for the reason that $r$, then $r$ can play an explanatory role with respect to $A^{\text {'s }} \Phi$ ing. ${ }^{7}$

When we ask this sort of "Why?" question, I think we are looking for a particular kind of explanation of the action. We are looking for an explanation that will make the action rationally intelligible. When Edna responds to our inquiry with some appeal to or presentation of the consideration that [THIN ICE], our inquiry has been satisfied. Edna has given the kind of response that puts her skating in a rationally intelligible light.

Now consider a slightly different case.

TWO SKATERS: Imagine two adjacent ponds. Edna takes it that the ice in the middle of one pond is thin. So, when she skates on it, she keeps to the edge of the pond. Edmund takes it that the ice in the middle of the other pond is thin. So, when he skates on it, he keeps to the edge of the pond. You are on a nearby hill, and you see both skaters skating — but you have no view about

\footnotetext{
${ }^{7}$ Sandis [2013: 30] rightly refers to this claim as a common "assumption" in the literature; resultantly, it is rarely explicitly stated or endorsed (although one can find hints of it in those like Alvarez [2011: 41n9] saying that "because" is factive). Kieran Setiya [2007: 39-47] provides a nice defense of the axiom if one is needed, even going so far as to argue that taking something to be a motivating reason just is taking it to be explanatory. Contemporary roots of this axiom are perhaps found in G. E. M. Anscombe [1957: 9ff].
} 
how things are with the ice. As they finish, you ask them both why they keep to the edge while they skate. They both tell you that the ice in the middle of the pond is thin. When you get home, your sister tells you that the ice in the middle of Edmund's pond is just fine.

Now, as with SKATING, I think that the natural way to understand this case is such that both Edna and Edmund act for the reason that [THIN ICE]. In TWO SKATERS, I think you would accept both responses to your "Why?" question without a fuss. Both Edna and Edmund have presented you with their reason for acting, which you can use to make sense of their actions. Furthermore, the information your sister gives you when you get home makes no difference to this. What your sister tells you about Edmund's pond does not leave you confused as to what Edmund was doing or why he was doing it. Despite the fact that Edmund was wrong about the way the world is, you can still understand his behavior by the thought that "His reason for keeping to the edge was that the ice in the middle of the pond is thin."

I am well aware that what I have just said is controversial (though in my view it should not be), and I will treat a serious objection to this analysis in the sixth section of the paper. Right now I want to treat an initial but ultimately superficial worry about what I have just said. Someone resisting my analysis might say: "I would not accept Edmund's answer to my 'Why?' question, since I do not accept that [THIN ICE]." My initial response to this worry is a simple reminder that in the case, you have no view about how things are with the ice at first. So I think you would accept his answer. Now, one might think, "But when I get home to my sister, I will realize that I should not accept his answer - since surely at that point I do not accept that [THIN ICE]." One might think this; but it would be puzzling. Of course, the information your sister gives you should lead you to reject Edmund's utterance "that [THIN ICE]" as an assertion. But what you learn from your sister should not prevent you from taking Edmund's answer as a statement of his reason, anymore than it should prevent you from receiving his answer as a statement of something he takes to be the case. Evidence for this is that, as I pointed out in the last paragraph, the 
information from your sister does not leave you reeling, in search of a (new) explanation of Edmund's action.

It is not important to settle what exactly to say about Edmund at this juncture. For now, one need only realize that it is not so unintuitive, pre-theoretically, to take Edmund's reason to be that [THIN ICE] even though it is not the case that [THIN ICE]. Indeed, I think that these previous considerations might suggest that the Nonfactive Viewm is more intuitive than the Factive Viewm. But it is enough for now to acknowledge that it seems possible, as I will say, to act in the light of a falsehood.

\section{AGting Rationally in the Light of a Falsehood}

As theorists, though, we might be interested not only in what agents' reasons for acting are or could be. We might also be interested in whether, when an agent acts for some reason or another, the agent is acting rationally in so doing. We might allow that, for example, Edmund acts for the reason that [THIN ICE] even though it is not the case that [THIN ICE]. But when he so acts, is his action rational?

To get at this question, consider a second pair of cases.

JUST SKATING: Imagine that Edmund is about to go skating. As he heads out, Edna tells him that the ice in the middle of the pond is thin. When Edmund goes out to the pond, the ice in the middle of the pond looks thin to him. Edmund takes it that the ice in the middle of the pond is thin. So, when he skates, Edmund keeps to the edge of the pond. Meanwhile, you are on a nearby hill, and you see Edmund skating. You approach him and ask him why he is skating as he is. He responds by saying that the ice in the middle of the pond is thin.

There is nothing unusual about this case. This is the kind of situation that any of us living near a pond might find ourselves in on a nice winter day. I think that any of us in this case would accept Edmund's response to our inquiry. If it occurred to us to ask the question at all (which, quite tellingly, I think, it would not), we would deem Edmund's action to be rational. I also think we 
would be right on both counts: Edmund does act for the reason that [THIN ICE], and Edmund's skating near the edge, in light of the consideration that [THIN ICE], is rational. Suppose though, that I add one detail to the case:

SKATING IN IGNORANGE: Imagine that Edmund is about to go skating. As he heads out, Edna tells him that the ice in the middle of the pond is thin. When Edmund goes out to the pond, the ice in the middle of the pond looks thin to him. Edmund takes it that the ice in the middle of the pond is thin. So, when he skates, Edmund keeps to the edge of the pond. Meanwhile, you are on a nearby hill, and you see Edmund skating. You approach him and ask him why he is skating as he is. He responds by telling you that the ice in the middle of the pond is thin. Unbeknownst to Edna, Edmund, and you, the ice in the middle of the pond is not thin.

Now, it seems to me that this second pair of cases is dialectically analogous to the first pair of cases, in the following way. We have the intuition about JUST SKATING that Edmund's skating is rational. Just as with the transition from SKATING to TWO SKATERS, adding the last detail here does nothing to alter our initial judgment. In moving from JUST SKATING to SKATING IN IGNORANCE, Edmund goes from having a true belief about the pond to having a false belief; but so far as the rationality of his action is concerned, nothing has changed.

Some may be tempted to deny what I have just said. That is, some will want to uphold the (intuitive) claim that Edmund's action is rational in JUST SKATING, but deny it in SKATING IN IGNORANCE. But doing this requires not just denying the intuitive verdict in such cases, but also denying plausible general claim about rationality. This is the claim that

error need not create irrationality: in some cases, the difference between $A$ 's being right about some bare empirical fact $p$ and $A$ 's being wrong about $p$ is not the kind of difference that can, on its own, make a difference to whether $A$ is $\Phi$ ing rationally. ${ }^{8}$

\footnotetext{
${ }^{8}$ Thanks to an anonymous referee here, whose comments helped me to formulate the claim in this way.
} 
There are some facts such that an agent's being wrong about them pretty clearly does impugn that agent's rationality. If Edmund thought that there being five clouds in the sky was reason to keep to the edge of the pond, for example, and this was the only consideration that he could mention in giving an account of his skating, we might have our doubts about the rationality of his action. But Edmund's being wrong about whether [THIN ICE] does not seem to fit this bill especially in cases like SKATING IN IGNORANCE, where Edmund seemingly has good reason to believe that [THIN ICE].

In the light of these considerations, I think that the plausible thing to say is that Edmund's skating near the edge is rational - even in SKATING IN IGNORANCE. It is possible, as I have said, to act rationally in the light of a falsehood. But what does this have to do with the factivity of normative reasons? To make the connection, consider one final case:

SENSELESS SKATING: Imagine that Edmund is about to go skating. As he heads out, Edna tells him that the weather is nice, and that it is a great day for skating. When Edmund goes out to the pond, he does not notice anything strange about the ice. So, when he skates, Edmund keeps to the edge of the pond. Meanwhile, you are on a nearby hill, and you see Edmund skating. You approach him and ask why he is skating as he is. He responds by telling you that the weather is nice, that it is a great day for skating, and that he noticed nothing strange about the ice.

Now, I think that any of us in this case would have our doubts as to the rationality of Edmund's action. Indeed, we may find it difficult to even make his action intelligible. I think that the most plausible explanation of these reactions is that we cannot find, anywhere in Edmund's account of his action, any good reason for doing what he is doing. This makes it hard to suppose that his action is rational; for an action to be rational, it is natural to think, it must be done for some good reason. Even independent of our judgments about cases like SENSELESS SKATING, this claim follows from a plausible (even if naive) conception of rationality itself. We naturally conceive of 
rationality as some kind of appropriate reasons-responsiveness. ${ }^{9}$ If acting rationally is, inter alia, responding appropriately to reasons, then an action must at least be an appropriate response to some consideration in order to be rational. But unlike his action in JUST SKATING and SKATING IN IGNORANCE, Edmund's action in SENSELESS SKATING shows no signs of this appropriate responsiveness.

\section{Motivating Reason to Slow the FaGtive TuRn}

We now have in place the materials for my master argument against the Factive Viewn of epistemic reasons. The argument goes as follows.

[1] In some cases where $A \Phi_{\mathrm{s}}$ for the reason that $r$, it is not the case that $r$.

[2] In some cases as described in [1], $A$ 's Фing is rational.

[3] $A$ 's $\Phi$ ing can be rational only if $A \Phi$ s for a good reason.

[4] In such cases as described in [2], $r$ must be a good reason for $\Phi$ ing.

[5] Some good reasons for $\Phi$ ing are things that are not the case.

[6] If the Nonfactive Viewn is true of practical reasons, then it is true of epistemic reasons.

[G] Some epistemic normative reasons are things that are not the case.

Premise [1] was provided by the intuitive claim that Edna and Edmund act for the same reason in TWO SKATERS. Premise [2] was provided by analogous judgments about Edmund in JUST SKATING and SKATING IN IGNORANCE, as well as the plausible principle that error need not create irrationality. Premise [3] was provided by a plausible explanation of our confusion about Edmund's action in SENSELESS SKATING, as well as the plausible analysis of rationality as some kind of appropriate reasons-responsiveness. Claim [4] follows from premises [1]-[3], on the simplifying assumption that, for example, [THIN ICE] is the only consideration Edmund is

\footnotetext{
${ }^{9}$ See Comesaña and McGrath [2014] for an example of a specification of this conception. There are some who, like Niko Kolodny, try to distinguish between rationality and reasons-responsiveness. I address an objection based on such a distinction in the sixth section. Thanks to Veli Mitova for pointing out the relevance of such views.
} 
responding to in IGNORANT SKATING. Claim [5] follows from claim [4]. Premise [6] is an application of the principle of uniformity argued for in section two. The conclusion, [G], follows from claims [5] and [6]: epistemic reasons for belief — or evidence, if you like ${ }^{10}$ - need not be facts.

The philosophical value of this argument, I hope you will agree, is not limited to its being a challenge to the Factive Viewn of epistemic reasons. As I said at the outset, it also demonstrates an important connection that some may find surprising: in order for one to defend the Factive Viewn of epistemic reasons, one must also defend the Factive Viewm of practical reasons.

\section{Gan the FaGtive Turn BE ForGed?}

I now want to briefly address three serious objections to this argument. My argument starts, in premise [1], with the thought that $A$ can $\Phi$ for the reason that $r$ even if it is not the case that $r$. But there has recently come a strong challenge to this claim in the literature on practical motivation. According to this challenge, the Nonfactive Viewn is at odds with the axiomatic claim that explanation is factive. The argument goes something like this: ${ }^{11}$

[O1] All motivating reasons are explanatory.

[O2] All things that are explanatory are facts.

[O3] Therefore, all motivating reasons are facts.

The first premise here is recognizable from earlier. Any time $A \Phi$ s for the reason that $r, r$ can play an explanatory role vis-á-vis $A$ 's $\Phi$ ing; there is a certain sense of the question "Why?" that will only be satisfied by appeal to the agent's motivating reason. The second premise is the axiomatic

${ }^{10}$ Here I follow Kelly [2009] in assuming that evidence is something like good epistemic reason to believe. A few have tried to challenge this conception, but as Kelly [2009: 5] notes, most assume that "reason to believe' and 'evidence' are more or less synonymous."

11 This seems to be the main argument responsible for garnering the Factive Viewm of practical reasons the support it currently enjoys. For a relevant sample of the discussion around this argument, see Alvarez [2010], Dancy [2011; 2014], Hornsby [2008], Hyman [2011], James Lenman [2011], McDowell [2013], and Sandis [2013]. 
claim that explanation is factive. Together, these two claims are supposed to show that the Nonfactive Viewm cannot be right; so my master argument has an implausible first premise.

This argument from the factivity of explanation deserves much more careful attention than it has so far received - careful attention that I cannot give it here. Instead, I want to cut right to the core of the argument, showing why I think it will ultimately fail as an objection to the Nonfactive Viewm. If this argument is sound, then the Nonfactive Viewn cannot give good reasons-explanations of actions done by agents like Edmund. That is: according to this argument, if it is not the case that $r, r$ is not capable of playing an explanatory role vis-á-vis any agent's Фing. But it seems quite clear to me that this is not so. In the third section, we observed that in the case of TWO SKATERS, we could explain Edmund's skating by appeal to his reason - despite his reason being a falsehood.

I now press a bit more on this issue. To see that this argument is faulty, all we need is an example of a satisfying reasons-explanation that makes use of a false reason. To that end, I think we can answer the question "Why is Edmund skating near the edge?" by saying that

His reason is that [THIN ICE].

This answer seems to me to be at least equal in explanatory power to the response that

He believes that [THIN ICE].

Both of these answers to the relevant "Why?" question seem perfectly natural and satisfying (though perhaps importantly different). Furthermore, the consideration that [THIN ICE] is indispensable to both of these explanations of Edmund's action. But neither of these answers implies or requires - in their own right, or as explanatory claims - that it is the case that [THIN ICE]. If the first explanation really is successful, it seems to follow that we can explain Edmund's 
action by appeal to his reason for acting, even though his reason is a falsehood. But if that is right, then the objection in question must be flawed. ${ }^{12}$

This first objection only challenges the Nonfactive View⿳ of practical reasons. Recall, though, that my central purpose is to show that the Nonfactive Viewn of practical reasons and the Factive Viewn of epistemic reasons are at odds. The next two objections, if successful, might provide a way to sever the connection here, and so resolve any potential tension. The first of these is an argument against premise [2]. According to this objection, although there might be something praiseworthy about what Edmund is doing, we should stop short of saying that his action is rational. In order for his action to be rational, it must be a response to some good reason for acting. But in cases like TWO SKATERS, for example, there are no good reasons for Edmund to do what he is doing. We know this because there is no feature of the world that favors his doing what he is doing. There is a feature that Edmund might think favors his skating near the edge, but alas, that feature is not a real feature of the situation. Since rationality consists in some appropriate reasons-responsiveness, we must stop short of saying that his action is rational.

I will address the second half of the objection below. I want now to address only the suggestion that we can stop short of saying that Edmund's action is rational. I have two things to say in response to this suggestion. The first is that, while Edmund's action may be ill-informed, it seems to be very difficult to say that it is irrational - that it is rationally impermissible. Aside from the plain intuitive judgment that this is so, the principle that error need not create irrationality supports this claim. So if we must say either that his action is rationally permissible or that it is rationally impermissible, we should surely say the former. My second response is to ask those hesitant to ascribe rationality to Edmund's action to consider what terms of appraisal they might find applicable in its stead. We might naturally say, for example, that his action is reasonable; that

\footnotetext{
12 A completely satisfying rebuttal of the argument would include an account of the flaw in the argument. I do not have the space to fully treat this issue here, since a full treatment, I think, would require a robust theory of explanation. But allow me to briefly sketch what I take the problem to be. The complication is that the notion of being explanatory is ambiguous. If being explanatory just means being the explanation, for example, the argument may be difficult for the Nonfactivist to maneuver around. But this seems to me not a very promising analysis. Being explanatory might also mean, for example, contributing to an explanation. On this understanding of the notion, the Nonfactivist can make use of the kind of maneuver I have just laid out.
} 
his action is perfectly sensible; his action is easily intelligible; his action is understandable; it is what any rational agent in his position would do; and so on. Indeed, I think that we can say all of these things without hesitation - and we would be correct in saying them. But with this cluster of concepts before me I now feel puzzled about the initial hesitation: it would be a fairly foreign, and perhaps somewhat artificial notion of rationality such that all of these things can truly be said of Edmund's action, and yet we cannot truly describe his action as rational. So I would invite anyone making this objection to provide and motivate that further conception of rationality. ${ }^{13}$

I will address a third and final objection before concluding. A third line of resistance is to concede premise [2], but not in any sense that implies that Edmund had good reason to do what he did. For example, we may be able to pinpoint considerations or features that allow us to give a rationalizing explanation of Edmund's action, or perhaps pick out some rational requirement that he satisfies. But these things do not strictly imply that there is any good reason for Edmund to be skating near the edge of the pond. So we can admit that Edmund's action is in some sense rational while resisting premise [3].

I have only one thing to say in response to this objection, which seems to me a hard point to maneuver around. It is, in many ways, the thought that makes the central argument of this paper compelling (if indeed it is compelling). The thought is this: if we grant that Edmund is acting for the reason that [THIN ICE], and that he is responding appropriately to that consideration, it requires a great deal of subtlety to proceed to say that he has no good reason for doing what he is. It seems to me undeniable that Edmund is responding to the consideration that the ice in the middle of the pond is thin. That is more or less a stipulation of the case. It also seems undeniable that Edmund is responding appropriately to this consideration. The appropriate thing to do, in the light of the consideration that [THIN ICE], is avoid the middle of the pond. We can ask the question: What makes this response appropriate? The very natural thought is that the consideration in question counts in favor of the response in question. I suppose, in a way, I can

${ }^{13}$ I do not want to create the impression that this is an impossible task. Littlejohn [2017], for example, has tried his hand at teasing some of these notions apart (thanks to an anonymous referee for bringing this to my attention). Adjudicating whether such projects are successful is beyond the scope of this paper. 
leave a challenge here similar to that which I left to the previous objection. The challenge is to provide and motivate accounts of being the favored response and being the appropriate response such that one can cleanly tease these things apart when dealing with characters like Edmund. I am skeptical that this can be done.

\section{CONGLUDING REMARKS}

There is one way out of my main argument that I have not discussed, and I should like to end by commenting on it. It is the piece of the second objection which I previously set aside for later. I know that there are many who have a sort of bedrock intuition that something that is not the case simply cannot favor anything. Some of those who have this thought may even find it to be more intuitive and plausible than each of the premises of my argument. Instead of resisting the validity or soundness of the argument directly, then, one might claim the conclusion of my argument constitutes a reductio of it; the link that I worked to establish between practical motivating reasons and epistemic normative reasons could possibly be used against me in this way. I can see two general ways in which this might be tried. The first is that one might treat my argument as a kind of paradox: even though it cannot be said exactly what the flaw is in the argument, we know that something must be wrong with it given the conclusion it arrives at. The second possibility is that one might think that the implausibility of the conclusion of my argument should lead us to reject one of the premises in the argument - perhaps whichever seems to be the weakest link.

Now, I am not sure how substantively I could proceed to debate my opponent who takes the first option here; but I also suspect that most will not be satisfied with that option. So I would like to close by making a couple of remarks about the second option. I anticipate that most of my opponents will find the first premise to be the weak link here. So, adopting the reductio strategy, one might say that my argument shows not that the Factive Viewn of epistemic reasons is false, but rather that the Nonfactive Viewm of practical reasons is false. I myself feel the pull of the thought that something that is not the case cannot favor anything - though not as strongly as I 
feel the pull of the thought that one can act for a reason that is not the case. But in any event, both claims on either end of the argument have some initial pull to them. This is part of what makes this way of refusing my argument unpersuasive to me. It seems that, in order to take my argument as a reductio of the Nonfactive Viewn, one must, in a way, privilege the favoring role of reasons in their ontology. That is, the thought must be something like this: any reason, whatever else it is, must be something that is capable of favoring. But this kind of favoring-first view of reasons is not at all appealing to me. It seems clear to me that the concept of a reason picks out the kind of thing that should, in principle, be capable of playing three roles: one motivational, one normative, and one explanatory. Of course, when things go well, one and the same consideration can play all three of these roles. But I see no reason at all to privilege one of these aspects over the others.

I have also began to wonder just how intuitive it is that something that is not the case cannot favor anything. I am increasingly tempted to think of the favoring relation as analogous, vis-á-vis factivity, to the logical implication relation. The fact that $P$ entails $Q$ for example, is not sensitive to the truth-value of $P$ or $Q$. That is: $P$ can stand in the entailment relation to $Q$ regardless of whether $P$ is true or $Q$ is true. ${ }^{14}$ The claim that "If it is raining, then it is wet" can be true whether or not it is raining (or wet). It is not unreasonable to imagine that the favoring relation might work similarly. Consider the claim "If it is raining, then I should bring an umbrella." It seems obvious to me that this claim can be true whether or not it is raining. But this is just a natural way of putting a thought about what I have good reason to do. I might as well have said, "Its raining favors my bringing an umbrella." But if that is so, then one claim can be placed in the favoring relation to another independent of the truth-value of either claim.

In any event, even one who does try to resist my argument by this kind of reductio has made a concession with which I would be pleased. I said at the outset that I had two main goals for this paper. One goal was to establish a surprising connection between the factivity of practical motivating reasons and the factivity of epistemic normative reasons. A second goal was to use

\footnotetext{
${ }^{14}$ For those sensitive to such things, this seems to me true also of probability relations: we can place $P$ and $Q$ in certain probability relations without thinking that either $P$ or $Q$ is true.
} 
this connection to construct a novel argument against the Factive Viewn of epistemic reasons. The one who adopts this kind of reductio strategy has at least conceded that I have accomplished my first goal. As to the second goal: I hope that the argument of this paper can do something to slow the factive turn in epistemology, even if it cannot bring it to a full stop. 


\section{REFERENGES}

Alvarez, Maria [2010]. Kinds of Reasons: An Essay in the Philosophy of Action. Oxford University Press.

Alvarez, MARIA [2016]. "Reasons for Action: Justification, Motivation, Explanation." Stanford Encyclopedia of Philosophy. Spring Edition.

Anscombe, G. E. M. [1957]. Intention. Harvard University Press. Second Edition, 1963.

Comesaña, Juan and Matthew MaGrath [2014]. "Having False Reasons.” In Clayton Littlejohn and John Turri (eds.), Epistemic Norms. Oxford University Press: 59-80.

Dancy, Jonathan [2000]. Practical Reality. Oxford University Press.

Dancy, Jonathan. [2003]. "Replies.” Philosophy and Phenomenological Research 67 (2): 468-490.

Dancy, Jonathan [2011]. "Acting in Ignorance." Frontiers of Philosophy in China 6 (3): 345-357.

Dancy, Jonathan [2014]. “On Knowing One's Reason.” In Epistemic Norms. Clayton Littlejohn and John Turri (eds.). Oxford University Press, 2014: 81-96.

Davidson, Donald [1980]. Essays on Actions and Events. Oxford University Press. Second Edition, 2001.

ENOCH, DAVID [2010]. "Not Just a Truthometer: Taking Oneself Seriously (but not Too Seriously) in Cases of Peer Disagreement." Mind 119 (476): 953-997.

Hornsby, Jennifer [2008]. "A Disjunctive Conception of Acting for Reasons.” Birkbeck ePrints. Also published in Disjunctivism: Perception, Action, Knowledge. Adrian Haddock and Fiona Macpherson (eds.). Oxford University Press, 2008: 244-261.

Hyman, John [1999]. “How Knowledge Works.” The Philosophical Quarterly 49 (197): 433-451.

Hyman, John [2010]. "The Road to Larissa." Ratio 23 (4): 393-414.

Hyman, John [2011]. "Acting for Reasons: Reply to Dancy.” Frontiers of Philosophy in China 6 (3): 358-368.

Kelly, Thomas [2008]. "Evidence: Fundamental Concepts and the Phenomenal Conception." Philosophy Compass 3 (5): 933-955.

Kelly, Thomas [2009]. "Evidence." Stanford Encyclopedia of Philosophy. Edward N. Zalta (ed.). Spring Edition.

Kolodny, Niko [2005]. "Why Be Rational?” Mind 114 (455): 509-563. 
Lenman, James [2011]. "Reasons for Action: Justification vs. Explanation.” Stanford Encyclopedia of Philosophy. Winter Edition.

LitTlejohn, Glayton [2012]. Fustification and the Truth-Connection. Cambridge University Press.

Littlejohn, Glayton [2013a]. "No Evidence is False.” Acta Analytica 28 (2): 145-159.

Littlejohn, Glayton [2013b]. "The Russellian Retreat.” Proceedings of the Aristotelian Society 113 (3): 293-320.

LitTlejohn, Glayton [2017]. "A Plea For Epistemic Excuses." Forthcoming in F. Dorsch and J. Dutant (eds.), The New Evil Demon. Oxford University press.

MaDowell, John [2013]. "Acting in the Light of a Fact," in Thinking About Reasons: Themes from the Philosophy of Jonathan Dancy, David Bakhurst, Brad Hooker, and Margaret Olivia Little (eds.). Oxford University Press: 13-28.

PARfit, Derek [2011]. On What Matters. Oxford University Press.

PryOR, JAMEs [2007]. "Reasons and That-Clauses." Philosophical Issues 17 (1): 217-244.

RAZ, JOSEPH [201 1]. From Normativity to Responsibility. Oxford University Press.

RyLe, GiLBerT [1949]. The Concept of Mind. 60th Anniversary Edition. Routledge, 2009.

Scanlon, T. M. [1998]. What We Owe to Each Other. Harvard University Press.

Schroeder, MARK [2008]. "Having reasons.” Philosophical Studies 139 (1): 57-71.

Smith, Michael [1992]. "Valuing: Desiring or Believing?” In Charles, David and Kathleen Lennon (eds.), Reduction, Explanation, and Realism. Oxford University Press, 323-360.

Unger, Peter [1975]. Ignorance: A Case for Scepticism. Oxford University Press, 2002 Edition.

Williams, Bernard [1981]. Moral Luck. Cambridge University Press.

Williamson, Timothy [2000]. Knowledge and its Limits. Oxford University Press.

Williamson, Timothy [2014]. "Acting on Knowledge”, in J. A. Carter, E. Gordon, and B. Jarvis (eds.), Knowledge-First. Oxford University Press. 